\title{
Criminal Justice and Behavior
}

http://cjb.sagepub.com

\section{Hypnosis and the Law: Examining the Stereotypes \\ Graham F. Wagstaff}

Criminal Justice and Behavior 2008; 35; 1277

DOI: $10.1177 / 0093854808321669$

The online version of this article can be found at:

http://cjb.sagepub.com/cgi/content/abstract/35/10/1277

\author{
Published by: \\ (3)SAGE \\ http://www.sagepublications.com \\ On behalf of: \\ International Association for Correctional and Forensic Psychology
}

Additional services and information for Criminal Justice and Behavior can be found at:

Email Alerts: http://cjb.sagepub.com/cgi/alerts

Subscriptions: http://cjb.sagepub.com/subscriptions

Reprints: http://www.sagepub.com/journalsReprints.nav

Permissions: http://www.sagepub.com/journalsPermissions.nav

Citations http://cjb.sagepub.com/cgi/content/refs/35/10/1277 


\title{
HYPNOSIS AND THE LAW \\ Examining the Stereotypes
}

\author{
GRAHAM F. WAGSTAFF \\ University of Liverpool, United Kingdom
}

\begin{abstract}
The traditional view of the hypnotized person as someone in a state of automatism, possessed of transcendent powers, is still popular among the general public. This has obvious implications for legal issues concerning possible coercion through hypnosis and the use of hypnosis for interviewing witnesses. However, it is now the opinion of most researchers that hypnosis does not induce a state of automatism, and caution should be exercised when employing hypnotic procedures to facilitate memory. It is concluded that better progress will be made in countering public misconceptions about hypnosis, and in benefiting from research on the applications of hypnotic interviewing procedures, if more effort is made to use concepts and terminology that relate hypnotic phenomena to everyday behavior and experience.
\end{abstract}

Keywords: hypnosis; memory; forensic interviewing; hypnotic coercion

\begin{abstract}
A large volume of research from countries including Britain, Germany, the United States, and Australia indicates that a popular image of a hypnotic participant is still that of a person in a "trance state," possessed of unusual powers, under the control of the hypnotist, with little awareness of what is going on (Daglish \& Wright, 1991; Green, Page, Rasekhy, Johnson, \& Bernhardt, 2006; Johnson \& Hauck, 1999; McConkey \& Jupp, 1986; Wagstaff \& Dockar, 1985; Wilson, Greene, \& Loftus, 1986). If there is any truth in such stereotypes, it is perhaps not surprising that the paths of hypnosis and law have crossed so often. For example, if hypnotized individuals are under the control of the hypnotist and are unaware of what is happening to them, then presumably they can be made to offend against their wills or become unwitting victims of crime and abuse. Also, if they are not in control of their actions, maybe people can be induced to tell the truth with hypnosis. Another popular stereotype of hypnosis is that it can be used to contact the unconscious mind and uncover hidden memories. If this is so, then hypnosis obviously has potential for helping witnesses recover important material during police investigations. But how accurate are these views? To address this question, it is useful first to look briefly at some general theoretical issues in modern hypnosis.
\end{abstract}

\footnotetext{
AUTHOR'S NOTE: Please direct correspondence to Professor G. F. Wagstaff, School of Psychology, University of Liverpool, Eleanor Rathbone Building, Bedford Street South, Liverpool, UK L69 7ZA; phone: 0151794 2949; fax: 0151794 2945; e-mail: gwf@Liverpool.ac.uk.
} 


\section{THE STATE VERSUS NONSTATE DEBATE}

Although hypnosis has traditionally been construed as an altered state or trance, this conception of hypnosis has long been a source of controversy (Barber, 1969; Barber, Spanos, \& Chaves, 1974; British Psychological Society, 2001; Heap, Oakley, \& Brown, 2004; Kirsch \& Lynn, 1995; Sheehan \& Perry, 1976; Wagstaff, 1981, 2004). Modern supporters of the "state" school continue to argue that central to the concept of hypnosis are alterations in the participant's psychological and/or physiological state or condition (see, for example, Bowers, 1983; Gruzelier, 2000; Hilgard, 1986, 1991; Killeen \& Nash, 2003; Woody \& Bowers, 1994; Woody \& Farvolden, 1998). However, although supporters of the sociocognitive or cognitive behavioral view also acknowledge that alterations in subjective experiences are core phenomena in the study of hypnosis, they reject the traditional notion of hypnosis as an altered state as misleading. Instead, the latter contend that various hypnotic phenomena, including changes in subjective experience, are best described and explained in terms of interactions between more mundane psychological processes, such as imagination, relaxation, role enactment, compliance, conformity, attention, attitudes, and expectancies (see, for example, Coe \& Sarbin, 1991; Kirsch, 1991; Lynn, 1992; Lynn \& Rhue, 1991a; Spanos, 1991; Spanos \& Chaves, 1989; Wagstaff, 1981, 1991, 2004). From this perspective, a hypnotized person is not someone who has fallen into a special altered psychological or physiological state but someone who is actively thinking and imagining along with, and responding to, suggestions and instructions delivered in a context defined as hypnosis. One result of debate on this issue is that terms such as "state" and "trance" tend to be less popular in definitions of hypnosis than they used to be; for example, although discussed, the concept of hypnosis as a state is not actually central to the definitions of hypnosis put forward by the American Psychological Association (1994; Green, Barabasz, Barrett, \& Montgomery, 2005) or the British Psychological Society (2001). Instead, it has become more common to refer to hypnosis not as a special state or condition but as a procedure or set of procedures. For example, hypnosis can be described as a set of procedures in which an individual receives (more or less any) instructions or suggestions to imagine and think about certain ideas, set in a context defined or labeled as hypnosis.

However, although the issue of whether hypnosis is best construed as an altered state remains unresolved, research in this area has done much to dispel the myth of the hypnotic participant as a passive automaton possessed of transcendent powers. For instance, a variety of evidence indicates that hypnotic participants tend to be active cognizing agents rather than passive responders, that much hypnotic behavior is comparatively easy to simulate, and that suitably instructed and motivated nonhypnotic control groups can equal and sometimes surpass the hypnotic groups on a variety of performance measures including cognitive capacities, feats of strength and endurance, and pain tolerance (see, for example, Barber, 1969; Barber et al., 1974; Lynn \& Rhue, 1991a; Spanos, 1991, 1992; Spanos \& Chaves, 1989; Wagstaff, 1981, 2004). Moreover, a variety of research has indicated that participants' descriptions of the experience of being hypnotized are indistinguishable from those of participants who have undergone, for example, relaxation training or instructions in the use of imagery (Barber et al., 1974; Kirsch, Mobayed, Council, \& Kenny, 1992). Nevertheless, although the research evidence and the opinions of many researchers and theorists in the academic community appear to run counter to many of the traditional stereotypes of hypnosis, these stereotypes clearly persist in the public mind. Why? 


\section{HYPNOSIS AND PSEUDOSCIENCE}

Perry (1992) asserted that the media perpetuate the popular stereotypes of hypnosis because of their commitment to entertain and to sell their products. Although this may be the case, perhaps equally important if not more important is the fact that hypnosis has long been associated with, and described in terms of, some very influential pseudoscientific rhetoric.

Since the early days of hypnosis, many investigators and commentators have preferred to take a range of ostensibly fantastic hypnotic phenomena (including $\mathrm{x}$-ray vision, regression to childhood and past lives, catalepsy, posthypnotic amnesia, and positive and negative hallucinations) at face value and to explain them by reference to special states and processes (such as magnetism, lucid sleep, monoideism, artificial somnambulism, and dissociation) rather than seriously entertain and systematically investigate more mundane explanations of the effects they claim to have demonstrated (Barber, 1969; Barber et al., 1974; Spanos, 1991, 1992; Spanos \& Chaves, 1989; Wagstaff, 1981, 1998). The legacy of this tradition is still very much with us; hence, terms such as "hypnotic trance," "hypnotic and waking states," and "dissociative states" remain in common use (see, for example, Bowers, 1983; Gruzelier, 2000; Hilgard, 1986, 1991; Killeen \& Nash, 2003; Woody \& Bowers, 1994; Woody \& Farvolden, 1998). Arguably, the more recent application of neuroscientific techniques to the investigation of hypnotic phenomena continues some elements of this tradition. Hence, the past two decades have seen the emergence of numerous reports allegedly demonstrating neurophysiological correlates of the hypnotic state, described in ever more complex anatomical and physiological jargon but without due emphasis on, or systematic consideration of, the range of more mundane social and cognitive processes that might account for these kinds of changes in the brain (Wagstaff, 1998, $2000,2004)$. It is perhaps, therefore, not really surprising that there continues to be a mismatch between the image of hypnosis perceived by often confused media and the public and the views of those conducting research in the area.

To illustrate some of these issues as they apply in the legal arena, and the possible advantages of construing hypnosis in terms of normal social and cognitive processes, let us consider the two major points of contact between hypnosis and the law identified earlier: the use of hypnosis as a coercive tool and the use of hypnosis as a memory enhancement procedure.

\section{HYPNOTIC COERCION IN REAL LIFE}

Can hypnotized persons be induced to commit immoral, criminal, or self-injurious acts of which they would normally be incapable? Although this question is an old one in the hypnosis literature, in practice, claims that people have unwittingly been hypnotized into committing criminal acts are rare and have generally been treated with skepticism (Barber, 1969; Conn, 1972; Udolf, 1983; Wolberg, 1972). For example, Wolberg (1972) wrote,

Dr. Jacob H. Conn . . . . read widely through one hundred and fifty years of medical literature and case histories and found no proof of a single violent crime committed under hypnosis. . . . Each subject could have committed the crime of which he was accused without the formality of hypnosis. (p. 279) 
One of the most famous cases of supposed coercion is that of Palle Hardrup in 1951 (Reiter, 1958). According to the standard account, Hardrup committed two bank robberies in Copenhagen, during which he shot dead two bank tellers. At the trial, evidence was presented to the effect that he had been under the influence of hypnosis at the time and was, therefore, not responsible for his actions. He was subsequently released, whereas his hypnotist, who had been a close friend, was given a life sentence. However, Hardrup was subsequently committed to an institution for the insane, where he changed his story, stating that the hypnotist had never hypnotized him. Summarizing cases-including the Hardrup case-Barber (1969) made the following points:

Two facts stand out: a) prior to the supposed introduction of hypnosis a close relationship had existed between the subject and the hypnotist; b) the relationship extended over a lengthy period of time, and involved strong emotional ties. . . . If hypnosis played a role in these cases, this role may have consisted in providing the subject with a rationale for justifying his behavior to himself and others. (p. 202)

Another typical case is that in the United Kingdom of R. v. Mohammed in 1989 (cited in Mottahedin, 1992). In this, two experts gave evidence that the female defendant had been hypnotized and brainwashed by her husband into committing the crime of attempted murder. However, the same kinds of factors present in the Hardrup case also applied here; that is, prior to the offense, there was a close manipulative relationship between hypnotist and participant that had existed over an extended period of time.

Rather more common are claims that victims have been reduced by hypnosis to helpless hypnotic automata and subjected to sexual assault without their consent and/or knowledge; some of these appear to have received more sympathetic consideration by the courts (Wagstaff, 1999a). The obvious difficulty with real-life situations, however, is that it is impossible to distinguish the effects of hypnosis from other causal factors that may have influenced the behaviors in question. For example, in addition to personal relationships and other motivational factors that may have existed prior to any sessions of hypnosis, the hypnotic situation itself involves strong social demands. By consenting to engage in hypnosis, the participant places himself or herself in a social situation in which he or she has tacitly agreed to trust the hypnotist and do what is instructed or suggested (Orne, 1962, 1970; Wagstaff, 1981). This is especially so when the context is defined as therapeutic; in such situations, as in counseling and psychotherapy generally, clients can develop a very powerful emotional bond with their therapists. Such situations are ripe for abuse, especially when the abuse is initially disguised by relaxation techniques; for example, in some cases, offenders have engaged in sexual assault having introduced the inappropriate physical contact as a relaxing hypnotherapeutic massage.

Because of the difficulties involved in controlling for these factors, researchers have turned to experimental methods to try to test the coercive powers of hypnosis.

\section{HYPNOTIC COERCION IN THE LABORATORY}

A few early reports claimed that hypnotized persons can be made to perform acts that are immoral or harmful to either themselves or others; such acts have included indecent exposure, picking up a dangerous snake, throwing acid at the experimenter, minor thefts, and verbal 
attacks. However, a number of reviewers of these studies have concluded that the notion of a hypnotic state is not necessary to explain these effects; rather, they occurred because either, contrary to outward appearances, participants perceived the situation to be safe or they considered that someone else would take responsibility for their actions (Barber, 1961, 1969; Coe, Kobayashi, \& Howard, 1972, 1973; Orne \& Evans, 1965; Udolf, 1983).

For example, Rowland (1939) and Young (1952) found that a majority of "deeply hypnotized" participants would attempt to pick up a dangerous snake and throw acid at the experimenter, whereas they generally refused to do this in the "waking state." However, Orne and Evans (1965) found that both hypnotic participants and participants instructed to simulate hypnosis would attempt to pick up a dangerous snake, plunge their hands into a beaker of concentrated nitric acid, and throw the acid at the experimenter when given emphatic suggestions to do so. Significantly, whereas five of six participants carried out the acts when hypnotized, only two of the same participants carried out the acts when not hypnotized; however, all six nonhypnotic simulators carried out the tasks. Other studies have shown that nonhypnotic participants are just as likely as (and sometimes slightly more likely than) hypnotic participants to perform a variety of antisocial or repugnant acts including mutilating the bible, cutting up the national flag (Levitt, Aronoff, Morgan, Overley, \& Parrish, 1975), signing derogatory-slanderous statements about a superior (Calverley \& Barber, 1965, cited in Barber, 1969), and even dealing heroin (Coe et al., 1972, 1973). These results fit in with a variety of other evidence that indicates that participants, regardless of whether hypnosis is used, are highly motivated to respond to the demands of the particular context (Orne, 1962, 1970; Wagstaff, 1981) and will readily perform what appear to be dangerous and antisocial acts if required to do so (see, for example, Milgram, 1974; Sheridan \& King, 1972).

Further evidence against the idea that hypnosis has a special coercive influence comes from a study by Wagstaff, Green, and Somers (1997). They hypothesized that the stereotype of the hypnotic automaton, out of control of his or her actions, would be more likely to be endorsed by those inexperienced in hypnosis than those who had experienced hypnosis - the rationale being that the latter would know from firsthand experience that hypnosis is not a state of automatism. Accordingly, in this study, two groups-one given an experience of hypnosis, the other not-were given a transcript of a court trial in which the defendant had committed a crime but claimed that he had done so against his will because he had been hypnotized. Of the experimental group who had not been hypnotized, many were willing to find him innocent. However, among those who had previously had an experience of hypnosis, not one was willing to find him innocent (i.e., none accepted the defense of automatism).

\section{HYPNOTIC COERCION, DISSOCIATED CONTROL, AND THE FRONTAL LOBES}

On the basis of the corpus of research in this area, there now seems to be a broad consensus among researchers in the field of hypnosis that hypnotic participants do not lose consciousness, control of their behavior, or their normal moral scruples (Lynn \& Rhue, 1991b). For example, the definition of hypnosis provided by the American Psychological Association (1994) states, "Contrary to some depictions of hypnosis in books, movies or television, people who have been hypnotized do not lose control over their behaviour" (p. 143). Similarly, having reviewed the scientific evidence, the independent panel appointed 
by the U.K. Home Office recommended that the public should be made explicitly aware of the fact that "the hypnotized subject retains ultimate control over his/her actions" (Home Office Review of the Hypnotism Act 1952, 1995, Annex D). The report by the British Psychological Society on the nature of hypnosis also states, "Although they may become very absorbed in the suggested ideas and images, subjects typically retain awareness of their environment and respond appropriately to it" (British Psychological Society, 2001, p. 4). And in a survey of 10 experts on forensic hypnosis conducted by Vingoe (1995), all rejected the view that "during hypnosis the control a person normally has over him or herself is in the hands of the hypnotist" (p. 180).

Nevertheless, on first consideration, despite this apparent consensus, an examination of some modern state theories of hypnosis presents a potentially more ambiguous picture. For example, one of the most influential modern state theories of hypnosis is dissociated control theory (Woody \& Bowers, 1994; Woody \& Farvolden, 1998). The theory is based on the assumption, derived from some models of working memory, that complex, will-driven tasks require the operation and intervention of a supervisory attentional system or central executive, much of which is located in the frontal lobes of the brain (see, for example, Norman \& Shallice, 1986). According to dissociated control theory, when in the hypnotic state, the frontal lobes are inhibited, reducing the influence of the supervisory attentional system, or executive processing, such that behavior becomes less critical and is triggered automatically by the commands of the hypnotist. Indeed, behaviorally, the hypnotized person is in a position equivalent to a clinical patient with frontal lobe damage. These ideas have also been incorporated into some other modern physiological theories of hypnosis; for example, Gruzelier (2000) argued that frontal inhibition is a fundamental feature of the hypnotic state. But if the hypnotized participant experiences frontal lobe inhibition, loses much of the capacity to engage in critical thinking, and is open to the control of the hypnotist, then, in theory at least, it looks like the idea of hypnotic automatism becomes viable.

Evidence for this view is, however, sparse and conflicting (Wagstaff, 2000, 2004; Wagstaff, Cole, \& Brunas-Wagstaff, 2007). For example, given that willed acts are associated with greater activity in the frontal cortex, one might expect activity in the frontal cortex to decrease during hypnosis; however, as Crawford (1996) noted, "Rather consistently there is increased involvement of regions within the frontal cortex during hypnotic suggestion" (p. 271). On the other hand, Gruzelier and Warren (1993) found that highly hypnotizable participants showed poorer performance on a phonemic fluency task immediately following an initial hypnotic induction procedure. As a variety of evidence indicates that phonemic fluency is related to executive and frontal processing, this would seem to fit with the idea that frontal function is impaired under hypnosis. But why should hypnotized participants show both increased activity in the frontal cortex and a reduction in frontal performance as measured by verbal fluency? Viewed in terms of ordinary psychological processes, these apparently contradictory results are quite predictable.

A standard hypnosis procedure typically involves concentration on and attention to various suggestions and instructions. One would expect such attention to be accompanied by both increased activity in the frontal cortex and a reduction in frontal performance. For example, in a study that did not involve hypnosis, Troyer, Moscovitch, and Winocur (1997) found that requiring participants to perform a finger-tapping task during a left frontal phonemic fluency test resulted in a reduction in performance on the latter. In other words, loading up the left frontal lobe with a secondary executive task resulted in a reduction in 
residual left frontal capacity and poorer performance on the verbal fluency task. In the same way, the simple (willed) act of concentrating hard on the hypnosis instructions might be expected to reduce residual frontal capacity and reduce performance on the verbal fluency task. Thus, to show a relative decline in the performance of activities related to the frontal cortex, one does not need to be in some unique hypnotic brain state and to have lost control of one's behavior. Rather, all one needs to be in is a frame of mind to concentrate hard on a competing task. Moreover, other data suggest that because of higher control baseline levels of phonemic fluency performance shown by participants classed as highly susceptible to hypnosis, the frontal performance of high hypnotizables during hypnosis is not actually significantly different from that shown in a nonhypnotic control condition by participants classified as unhypnotizable (Gruzelier \& Warren, 1993; Wagstaff, Cole, \& BrunasWagstaff, 2007).

So although there is some evidence that performance on a frontal task may decline when participants are receiving hypnotic suggestions, there is no evidence that this relates to a loss of control over their behavior. Indeed, the main advocate of dissociated control theory, Erik Woody, has since acknowledged this. Hence, he said, "Common misconceptions are that hypnosis can be used to enable people to demonstrate abilities they would not otherwise possess, and make people engage in behavior they would otherwise avoid because of ethical and moral constraints. Neither of these is true" (Woody, 1998, p. 2).

\section{AUTOMATISM, INVOLUNTARINESS, AND DURESS}

The potentially ambiguous status of dissociated control theory illustrates that despite the broad consensus among researchers in the field that hypnotized participants do not lose awareness or control of their behavior, progress in communicating this view to the media and general public is likely to require the clarification of some fundamental and conceptual and semantic issues. One issue that may require particular attention is that of involuntariness.

Many researchers put considerable stress on the fact that hypnotic participants often report their responses as occurring involuntarily. Indeed, this has been construed by some as one of the defining features of hypnosis (Bowers, 1983; Orne, 1966). However, as many commentators have emphasized, the fact that hypnotic behaviors may sometimes be experienced as involuntary does not mean that the participants have lost control of these behaviors (see, for example, Gorassini, 1999; Kihlstrom, 2004; Lynn, Rhue, \& Weekes, 1990; Wagstaff, 2004). For instance, in response to an ideomotor suggestion such as arm lowering ("your arm is getting heavy"), good hypnotic participants may become absorbed in imagery designed to make their arms feel heavy, or when moving their arms, they may focus attention away from thoughts such as "I am moving my arm." As a consequence, the movement may be experienced as involuntary, but this does not mean that they have lost control of their behavior and cannot disengage from the process. Indeed, a variety of evidence shows that hypnotized participants will readily modify, resist, and even oppose responding to suggestions if the social demands indicate that responding is no longer required or appropriate (Kihlstrom, 2004; Lynn, Nash, Rhue, Frauman, \& Sweeney, 1984; Silva \& Kirsch, 1987; Spanos, 1986, 1991, 1992; Spanos \& Chaves, 1989; Spanos, Cobb, \& Gorassini, 1985; Wagstaff, 1981, 2004). 
Nevertheless, it should also be emphasized that even if hypnotic automatism is excluded as a key variable in legal cases where the abuse of hypnosis is alleged, this should not stop us from examining alternative causes. As noted earlier, an unscrupulous hypnotist (such as an unscrupulous doctor or counselor) can use a variety of factors to induce submission, including trust, rapport, relaxation, fear of embarrassment, ambiguity, and physical manipulation. In English law, a distinction is made between the concept of "compulsion" or "duress"- as when, for instance, an action was performed under threat, in obedience to orders, under marital coercion, or to avert a greater evil — and "automatism" — as when, for instance, an action was performed without awareness or as the result of a spasm (Curzon, 1980). Given the evidence, it would perhaps make more sense in such cases for investigators to pay attention more to the elements of the hypnotic situation that might be relevant to the concept of compulsion or duress rather than automatism.

\section{HYPNOSIS, TRUTH TELLING, AND FAKING}

Given the broad agreement that hypnotized individuals do not lose control of their behavior, it is not surprising that the issue of whether a person can lie under hypnosis seems to have been settled for some time now. The general opinion among researchers is that participants are capable of lying when hypnotized (see, for example, American Medical Association, 1986; Anderton, 1986; Orne, 1971; Orne, Soskis, Dinges, \& Orne, 1984; Reiser, 1980; Udolf, 1983). In an experimental investigation of this issue, Sheehan and Statham (1988) suggested that highly hypnotizable participants may find it more difficult to lie under hypnosis because, having developed a rapport with the hypnotist, they may subsequently find that deceiving the hypnotist creates conflict. However, this interpretation was based on the response of a single participant; moreover, it suggests that it is not the induction of hypnosis, per se, that is responsible for any difficulty in lying but the social relationship established between the hypnotist and the participant. In a further study, in which group induction of hypnosis was used (i.e., rapport was minimized), Sheehan and Statham found that participants of high hypnotizability (i.e., those who had had a firsthand experience of hypnosis) were no more likely than low hypnotizables (who had not experienced hypnosis) to endorse the opinion that lying is possible under hypnosis.

In regard to faking hypnosis itself, there are indications that statistically, at a group level, participants instructed to simulate hypnosis can be detected because they tend to show exaggerated behavior and respond like very highly hypnotically susceptible participants (Martin \& Lynn, 1996; Wagstaff, 1981, 2004). For example, Martin and Lynn (1996) devised a Hypnotic Simulation Index, which measures the extent to which participants report extreme experiences (including simply how "deeply hypnotized" they were). They showed that a 10-item version of the Hypnotic Simulation Index successfully discriminated reals from simulators (low hypnotizables instructed to simulate an "excellent" hypnotic participant) for $96 \%$ of the sample. The simulators tended to report more extreme experiences. Significantly, however, a standard hypnotic susceptibility test also successfully classified $76 \%$ of the sample. Such results fit well with the view put forward by Wagstaff (1991, 2004) and Spanos (1992) that participants who provide extreme scores on hypnotic susceptibility measures (hypnotic "virtuosos") are those most likely to be complying or exaggerating their responses. However, an alternative view is that those simulating the role of an 
excellent hypnotic participant are actually indistinguishable from the small percentage of participants who tend to become the most profoundly hypnotized. We also do not know how well the Hypnotic Simulation Index would perform in detecting someone not attempting to simulate an excellent hypnotic participant.

Thus, although the results using the Hypnotic Simulation Index seem promising, for the present, beyond the grounds of common sense (for instance, a drunk laughing and giggling while purporting to be hypnotized is unlikely to be taken seriously) and other more general techniques to detect lying (such as the polygraph; but see Iacono, 2008), there is no reliable measure that can tell us whether a particular individual is "faking hypnosis" (for further discussion, see Wagstaff, 1999a).

\section{HYPNOSIS AND MEMORY FACILITATION}

The view that hypnosis does not induce a state of automatism could be seen as good news for those wishing to promote the use of hypnosis as a memory enhancement tool; nevertheless, the evidence for the use of hypnosis in this role has also been the source of some controversy. In the late 1970s and early 1980s, a number of reports indicated that hypnosis was being used quite extensively as a memory enhancement procedure by the police in a number of countries (for example, Haward, 1988; Haward \& Ashworth, 1980; Hibbard \& Worring, 1981; Kleinhauz, Horowitz, \& Tobin, 1977; Reiser, 1980). However, although memory facilitation effects with hypnosis have occasionally been reported in laboratory experiments and in the field (for example, Geiselman, Fisher, MacKinnon, \& Holland, 1985; Hibbard \& Worring, 1981; Ready, Bothwell, \& Brigham, 1997; Reiser, 1980), there now seems to be a fairly overwhelming body of experimental evidence to indicate that hypnotic procedures do not improve the accuracy of memory (as determined by the proportion of correct to incorrect responses) to a level greater than that achievable in motivated nonhypnotic conditions (for reviews, see Erdelyi, 1994; Kebbell \& Wagstaff, 1998; McConkey \& Sheehan, 1996; O’Connell, Shor, \& Orne, 1970; Sanders \& Simmons, 1983; Smith, 1983; Steblay \& Bothwell, 1994; Wagstaff, 1984, 1989, 1999a, 1999b; Webert, 2003).

In an important overview of the relevant literature on memory facilitation with hypnosis, Erdelyi (1994) found that in some cases, hypnosis did result in increases in correct responses; however, when they occurred, increases in correct responses with hypnosis were more or less confined to situations that require free recall of high-sense materials (filmed crimes, staged incidents, etc.). Significantly also, in such cases, hypnosis also tended to increase the number of incorrect responses such that overall accuracy, as determined by the proportion of correct to incorrect responses, was not improved. In fact, sometimes the increase in incorrect responses was such that overall accuracy deteriorated (see, for example, Dinges et al., 1992; Dywan \& Bowers, 1983). Research also suggests that hypnosis may encourage witnesses to incorporate more misleading information into their reports and to be more confident in their reports generally, regardless of accuracy, resulting in a false confidence effect (McConkey \& Sheehan, 1996; Scoboria, Mazzoni, Kirsch, \& Milling, 2002; Sheehan \& Tilden, 1983; Spanos, Quigley, Gwynn, Glatt, \& Perlini, 1991; Wagstaff, BrunasWagstaff, Knapton, et al., 2004).

Because of the potential problem of memory errors with hypnosis, there has been a tendency for some authorities to change their emphasis. Hence, instead of viewing hypnosis 
as a potentially valuable tool for uncovering accurate memories, they consider it to be a liability (Diamond, 1980; Orne, 1979; Webert, 2003). Indeed, as a result of expert evidence on this subject, in the United States, in the majority of states in which the issue has come to court, a per se exclusion rule has been applied such that victims and witnesses who have been interviewed with hypnosis have been banned from giving evidence in court (Webert, 2003). However, it has been found necessary to exclude defendants from this ban, as this would affect the defendant's constitutional right to testify and call witnesses on his or her behalf. In the United Kingdom, the Home Office (1988) has also produced guidelines discouraging the use of hypnosis as a police interviewing tool. If we assume that hypnosis is some sort of unusual brain state that reduces critical reasoning and produces irreversible memory distortions, then, of course, it might make sense to place a ban on hypnotically elicited testimony and hypnotic memory enhancement techniques generally. Viewed in terms of normal social and cognitive processes again, however, things may not be quite as negative as at first they might seem.

The most generally accepted explanation for the false memory effect is that because of the expectancies associated with hypnosis and pressure brought to bear by the investigating hypnotist to remember more, hypnotized witnesses sometimes adopt a more lax criterion for report (Wagstaff, 1999a, 1999b; Webert, 2003). To most participants, it is fairly obvious that hypnotic procedures are expected to enhance accurate memory (indeed, in many experiments, explicit instructions are given to this effect). For example, Wagstaff, Vella, and Perfect (1992) found that participants simulating jurors were more likely to believe testimony if they were told it had been elicited under hypnosis. Hypnotized participants may therefore attempt to fulfill this requirement by giving some additional details about which they were previously unsure, resulting in increases in incorrect information. In addition, because of a belief that hypnosis improves memory, some participants may report vague details or imaginings as confident memories, assuming that because they are created in the hypnotic context, they must be accurate (Lynn \& Nash, 1994; Webert, 2003). In support of this view, a variety of evidence suggests that hypnotically created pseudomemories and false confidence effects can be reduced to nonhypnotic levels under conditions that encourage more cautious and truthful reporting, such as when participants are told that a "hidden-part" of them can describe their "real" memories, when they are cross-examined under oath (Spanos, Gwynn, Comer, Baltruweit, \& de Groh, 1989), when they are given a financial incentive for accurate reporting (Murray, Cross, \& Whipple, 1992), or when they are given an opportunity to deny being in a trance (Wagstaff \& Frost, 1996). False memory reports with hypnosis are also reduced when it is implied that the experiment is terminated (Barnier \& McConkey, 1995), when participants are contacted by telephone at their home after the experiment (McConkey, Labelle, Bibb, \& Bryant, 1990), and when rapport with the hypnotist is downgraded (Sheehan, Green, \& Truesdale, 1992).

The exact extent to which hypnotically induced pseudomemories are reversible, or can be reduced by warnings, has been a matter of some controversy (Green, Lynn, \& Malinoski, 1998). Research using a range of more forensically relevant items suggests that the extent to which hypnotically created pseudomemories are reversible depends crucially on participants' perceptions about how their disavowals are likely to be evaluated by others (Spanos et al., 1989). It seems, therefore, that in the short term, and for some participants at least, pseudomemories attributable to the influence of hypnotic procedures are more likely to reflect reporting biases rather than permanent memory distortions. It can also be 
noted that memory inaccuracies are more likely to occur as a result of factors such as leading questions than the induction of hypnosis per se (Scoboria et al., 2002).

Notwithstanding the bulk of the laboratory evidence, it is significant that some experts have continued to argue that hypnosis can usefully improve memory, and police in a number of countries have continued to use hypnosis for memory enhancement purposes (see, for example, McConkey \& Sheehan, 1996; Vingoe, 1995; Wagstaff, 1999a, 1999b). The main reason for this is that despite the experimental findings, a number of anecdotal cases have allegedly shown hypnosis to be effective in this role. One of the most famous cases is that in the United States of Beck v. Norris (see Webert, 2003). In this case-which occurred in 1986, before the widespread adoption of the per se exclusion rule-five witnesses who underwent hypnosis produced a new composite sketch of the suspect. This was later independently verified as the defendant and led to a successful conviction. But why should case studies of the effects of hypnotic interviewing look so much more impressive than the experimental research findings?

Again, if we consider hypnosis in terms of normal social and cognitive processes, a number of explanations emerge. For example, in the field, there are a number of techniques that so-called hypnoinvestigators have employed in forensic investigations that might produce better results than routine police interrogation (Wagstaff, 1982a, 1982b). Techniques used by hypnoinvestigators have included sympathetic nonauthoritarian interrogators who establish trust and rapport, repeated testing, and techniques to provide memory retrieval cues, such as role-playing, picture drawing, recalling in different orders, and hypnotic revivication or context reinstatement (i.e., reporting everything, including thoughts and feelings). In addition, hypnoinvestigators have tended to be more skilled at avoiding problems associated with standard police interviewing (Wagstaff, 1999b). For example, police interviewers frequently interrupt the witnesses. Such interruptions may disrupt concentration, impairing the ability to remember information, and result in short responses that may exclude important details. Most police interviewers also rely heavily on the use of closed questions (such as "Was he wearing a hat?") rather than open-ended ones (such as "Describe your attacker"). Closed questions tend to result in short, truncated answers, and the only information elicited is that which is requested. In contrast, the procedures employed by hypnoinvestigators encourage less interruption and give the witness an opportunity to elaborate freely when giving his or her account.

Because of this, attempts have been made to direct the police toward nonhypnotic means of memory enhancement that share the kinds of techniques developed by hypnoinvestigators (Wagstaff, 1982a, 1982b, 1999a, 1999b). The most popular of these is the cognitive interview, which uses techniques such as rapport building; open, "report everything" instructions; focused attention; and context reinstatement (Fisher \& Geiselman, 1992). When the comparison has been made, similar memory enhancement has been shown with both the cognitive and hypnotic interviews (Geiselman et al., 1985). However, because of the practical problems associated with the use of hypnosis, the cognitive interview has generally displaced hypnosis as the preferred mode of memory facilitation in police investigations in the United Kingdom and United States. For example, although the cognitive interview can sometimes also produce an increase in both correct and incorrect information, there is no actual reduction in accuracy as determined by the proportion of correct to incorrect responses (Kohnken, Milne, Bull, \& Memon, 1999). Nevertheless, experience in the field suggests that cognitive interviewing is time-consuming in terms of not only time spent 
interviewing the witness but also training the police interviewers. Moreover, because of their complexity, officers often do not adhere to the specified procedures (Kebbell, Milne, \& Wagstaff, 1999; Kebbell \& Wagstaff, 1999). Significantly, Geiselman et al. (1985) found that although similar memory enhancement was shown with both cognitive and hypnotic interview techniques, the latter took less time to conduct. Consequently, rather than dismissing the notion of hypnotic memory enhancement altogether, there may be merit in reexamining components of hypnotic interviewing that may be useful in their own right and may not require excessive time and training to administer (Wagstaff, Brunas-Wagstaff, Cole, \& Wheatcroft, 2004; Wagstaff, Brunas-Wagstaff, Knapton, et al., 2004; Wagstaff, Cole, Wheatcroft, Marshall, \& Barsby, 2007).

\section{A COMPONENTIAL APPROACH TO HYPNOTIC INTERVIEWING}

As a starting point, Wagstaff, Brunas-Wagstaff, Knapton, et al. (2004) noted that similarities between the effects produced by standard relaxation-based hypnotic induction procedures and other procedures such as systematic relaxation, autogenic training, and meditation have often been commented on. For example, Benson and Klipper (1976) argued that these procedures share in common the adoption of a relaxed, passive mode of thinking, brought about by focusing of attention on some neutral target or set of targets, such as parts of the body or breathing, while ignoring distracting thoughts. According to Wagstaff, Brunas-Wagstaff, Knapton, et al., it is possible that such procedures might facilitate memory for certain kinds of material. For example, such procedures may facilitate memory by reducing distractions and encouraging a more holistic or global mode of information processing along with an increase in nonexecutive, right hemisphere processing. A variety of evidence suggests that these factors may facilitate memory for faces and memory for meaningful emotional material - the kinds of materials for which, according to Erdelyi (1994), hypnosis is most likely to facilitate correct responses (Wagstaff, BrunasWagstaff, Cole, et al., 2004; Wagstaff, Brunas-Wagstaff, Knapton, et al., 2004).

With these considerations in mind, Wagstaff, Brunas-Wagstaff, Knapton, et al. (2004) investigated the effects on memory of a focused meditation (FM) procedure, which involved little more than 1.5 minutes of deep breathing. The idea was that this would share some features of hypnotic induction (such as concentration, attention, and relaxation) but without the contextual label of "hypnosis," that is, without the bothersome feature that might engender the expectancies that could lead to false alarms and false confidence effects typically associated with hypnosis. Wagstaff, Brunas-Wagstaff, Knapton, et al.'s results showed that compared to control procedures, this very brief FM procedure facilitated face recognition and also free recall for an emotional event (Princess Diana's funeral) without the characteristic false errors and inflated confidence levels associated with traditional hypnotic techniques (Wagstaff, Brunas-Wagstaff, Cole, et al., 2004; Wagstaff, Brunas-Wagstaff, Knapton, et al., 2004; Wagstaff, Cole, Wheatcroft, et al., 2007).

In a further study, Hammond, Wagstaff, and Cole (2006) found that for both adults and children, FM and a context reinstatement procedure enhanced performance on both openended and closed questions to levels greater than those achieved by controls. However, whereas context reinstatement also resulted in elevated levels of confidence in relation to incorrect responses on closed questions, FM did not have this effect. Most recently, 
Wagstaff, Cole, Wheatcroft, et al. (2007) demonstrated that a combined context reinstatement and FM procedure was more effective than context reinstatement alone in facilitating memory for an emotional event, without the increase in false positive errors familiar to more traditional hypnosis techniques.

Another potentially influential variable is eye closure. Eye closure is common to most hypnotic procedures, and previous pilot work suggests that eye closure at retrieval may be a useful memory aid in its own right (Wagstaff, 1982a). There are a number of possible reasons for this. For example, it could be that eye closure simply cuts out visual interference and aids concentration. Accordingly, Wagstaff, Brunas-Wagstaff, Knapton, et al. (2004) also looked at the effects of eye closure. They found that independent of FM, eye closure was effective in facilitating free recall of an event without an increase in errors; however, a combination of both was most effective. The enhancing effect of eye closure also has been shown more recently by Perfect et al. (2007).

In sum, it seems that earlier claims that hypnotic investigative procedures, both in the laboratory and in the field, had the potential to enhance memory perhaps were not entirely unfounded. However, one does not need to postulate special hypnotic processes to explain such effects. Indeed, it seems that more often than not, any beneficial effects were masked by increases in errors due to the labeling of the context as hypnosis, with its implied magical properties.

\section{HYPNOSIS AND THE RECOVERY OF EARLY MEMORIES OF ABUSE}

Some of these considerations have obvious implications for the debate as to whether hypnosis can be used to recover previously unreported, allegedly "repressed," childhood memories of abuse (Lynn \& Nash, 1994; Ofshe \& Watters, 1996). Although some academics and clinicians have tended to adopt rather polarized positions on this issue, the actual empirical evidence could be construed as supporting both sides of this debate. For instance, whereas participants put through hypnotic interviewing procedures may report false information about early life experiences, particularly if led to do so (Green, 1999; Marmelstein \& Lynn, 1999), it does not follow that all additional information recalled using hypnosis will necessarily be inaccurate. To some extent, factors present in hypnosis procedures such as eye closure, meditation, and context reinstatement could also help to reinstate accurate memories. Moreover, in the guise of a special memory facilitation technique, set in a context that encourages trust and rapport, hypnosis may act as a face-saving device, giving witnesses permission to talk about events that they might previously have been reluctant to mention. This would help to explain a sudden emergence of (independently corroborated) reports of extensive periods of abuse that people would not normally be expected to forget, without postulating the involvement of a special psychological mechanism such as repression (Wagstaff, 1999b).

\section{CONCLUSION}

Contrary to popular public opinion, the research evidence suggests that hypnosis procedures do not make people into helpless automata. Hypnosis is not a truth serum, and it is 
not a magical way of contacting the unconscious and uncovering lost memories. Indeed, by endorsing and promoting the popular stereotypes of hypnosis, many hypnosis practitioners have effectively been hoisted with their own petard; that is, by describing hypnosis as a special trance or brain state, they may have unwittingly laid themselves open to accusations of abuse allegedly committed while their victims were unaware of what was happening to them and/or unable to resist. Moreover, by emphasizing the unique properties of hypnosis to access hidden memories, they may have encouraged the creation of pseudomemories and thereby the demise of hypnosis as a memory facilitation technique.

To counter misconceptions about hypnosis, the obvious message is that experts in the area of hypnosis should be more sensitive to problems of misinterpretation. For example, instead of describing hypnosis with references to traditional concepts such as the hypnotic trance or altered state of awareness, academic researchers, clinicians, and other practitioners perhaps should adopt an approach that uses concepts and terminology that relate hypnotic phenomena more to everyday behavior and experience-such as attention, concentration, and imagination. Such an approach might also encourage experts to be more open-minded about hypnosis. For example, the evidence clearly suggests that memory enhancement procedures explicitly labeled as hypnosis should be used with caution, and it makes sense to recommend that the police use the cognitive interview and other procedures such as meditation, context reinstatement, and eye closure instead. But it does not follow that investigative hypnosis is so dangerous that it should be banned outright as an investigative technique and that anyone who has previously been hypnotized should be banned from testifying, as a matter of routine. Indeed, the procedures adopted in hypnotic investigative interviewing may yet provide a rich source of ideas and techniques that may benefit forensic interviewing in the future.

\section{REFERENCES}

American Medical Association. (1986). Council report: Scientific status of refreshing recollection by the use of hypnosis. International Journal of Clinical and Experimental Hypnosis, 34, 1-12.

American Psychological Association, Division of Psychological Hypnosis. (1994). Definition and description of hypnosis. Contemporary Hypnosis, 11, 143.

Anderton, C. H. (1986). The forensic use of hypnosis. In F. A. De Piano \& H. C. Salzberg (Eds.), Clinical applications of hypnosis (pp. 197-223). Norwood, NJ: Ablex.

Barber, T. X. (1961). Antisocial and criminal acts induced by "hypnosis": A review of clinical and experimental findings. Archives of General Psychiatry, 5, 301-312.

Barber, T. X. (1969). Hypnosis: A scientific approach. New York: Van Nostrand.

Barber, T. X., Spanos, N. P., \& Chaves, J. F. (1974). Hypnotism, imagination, and human potentialities. New York: Pergamon.

Barnier, A. J., \& McConkey, K. M. (1995). Reports of real and false memories: The relevance of hypnosis, hypnotizability, and the context of memory test. Journal of Abnormal Psychology, 101, 521-527.

Benson, H., \& Klipper, M. Z. (1976). The relaxation response. London: Collins.

Bowers, K. S. (1983). Hypnosis for the seriously curious. New York: Norton.

British Psychological Society. (2001). The nature of hypnosis. Leicester, UK: Author.

Coe, W. C., Kobayashi, K., \& Howard, M. L. (1972). An approach toward isolating factors that influence antisocial conduct in hypnosis. International Journal of Clinical and Experimental Hypnosis, 20, 118-131.

Coe, W. C., Kobayashi, K., \& Howard, M. L. (1973). Experimental and ethical problems of evaluating the influence of hypnosis in antisocial conduct. Journal of Abnormal Psychology, 82, 476-482.

Coe, W. C., \& Sarbin, T. R. (1991). Role theory: Hypnosis from a dramaturgical and narrational perspective. In S. J. Lynn \& J. W. Rhue (Eds.), Theories of hypnosis: Current models and perspectives (pp. 303-323). New York: Guilford.

Conn, J. H. (1972). Is hypnosis really dangerous? International Journal of Clinical and Experimental Hypnosis, 20 , 61-79.

Crawford, H. J. (1996). Cerebral brain dynamics of mental imagery: Evidence and issues for hypnosis. In R. G. Kunzendorf, N. P. Spanos, \& B. J. Wallace (Eds.), Hypnosis and imagination (pp. 253-282). New York: Baywood. 
Curzon, L. B. (1980). Criminal law. Plymouth, UK: Macdonald and Evans.

Daglish, M. R. C., \& Wright, P. (1991). Opinions about hypnosis among medical and psychology students. Contemporary Hypnosis, 8, 51-55.

Diamond, B. L. (1980). Inherent problems in the use of pre-trial hypnosis on a prospective witness. California Law Review, 68, 313-349.

Dinges, D. F., Whitehouse, W. G., Orne, E. C., Powell, E. W., Orne, M. T., \& Erdelyi, M. H. (1992). Evaluating hypnotic memory enhancement (hypermnesia and reminiscence) using multitrial forced recall. Journal of Experimental Psychology: Learning, Memory, and Cognition, 18, 1139-1147.

Dywan, J., \& Bowers, K. (1983). The use of hypnosis to enhance recall. Science, 22, 184-185.

Erdelyi, M. W. (1994). The empty set of hypermnesia. International Journal of Clinical and Experimental Hypnosis, 42, 379-390.

Fisher, R. P., \& Geiselman, R. E. (1992). Memory enhancing techniques for investigative interviewing: The cognitive interview. Springfield, IL: Charles C Thomas.

Geiselman, R. E., Fisher, R. P., MacKinnon, D. P., \& Holland, H. L. (1985). Eyewitness memory enhancement in the police interview: Cognitive retrieval mnemonics versus hypnosis. Journal of Applied Psychology, 70, 401-412.

Gorassini, D. R. (1999). Hypnotic responding: A cognitive-behavioral analysis of self-deception. In I. Kirsch, A. Capafons, E. Cardena-Buelna, \& S. Amigo (Eds.), Clinical hypnosis and self-regulation: Cognitive-behavioral perspectives (pp. 73-104). Washington, DC: American Psychological Association.

Green, J. P. (1999). Hypnosis, context effects and the recall of early biographical memories. International Journal of Clinical and Experimental Hypnosis, 47, 284-300.

Green, J. P., Barabasz, A. F., Barrett, D., \& Montgomery, G. H. (2005). Forging ahead: The 2003 APA Division 30 definition of hypnosis. International Journal of Clinical and Experimental Hypnosis, 53, 259-264.

Green, J. P., Lynn, S. J., \& Malinoski, P. (1998). Hypnotic pseudomemories, prehypnotic warnings and the malleability of suggested memories. Applied Cognitive Psychology, 12, 431-444.

Green, J. P., Page, R. A., Rasekhy, R., Johnson, L. K., \& Bernhardt, S. E. (2006). Cultural views and attitudes about hypnosis: A survey of college students across four countries. International Journal of Clinical and Experimental Hypnosis, 54, 263-280.

Gruzelier, J. (2000). Redefining hypnosis: Theory, methods, and integration. Contemporary Hypnosis, 17, 51-70.

Gruzelier, J., \& Warren, K. (1993). Neuropsychological evidence of reductions on left frontal tests with hypnosis. Psychological Medicine, 23, 93-101.

Hammond, L., Wagstaff, G. F., \& Cole, J. (2006). Facilitating eyewitness memory in adults and children with context reinstatement and focused meditation. Journal of Investigative Psychology and Offender Profiling, 3, 117-130.

Haward, L., \& Ashworth, A. (1980, March). Some problems of evidence obtained by hypnosis. Criminal Law Review, pp. 469-485.

Haward, L. R. C. (1988). Hypnosis by the police. British Journal of Experimental and Clinical Hypnosis, 5, 33-35.

Heap, M., Oakley, D., \& Brown, R. (2004). The highly hypnotisable person. London: Brunner-Routledge.

Hibbard, W. S., \& Worring, R. W. (1981). Forensic hypnosis: The practical application of hypnosis in criminal investigation. Springfield, IL: Charles C Thomas.

Hilgard, E. R. (1986). Divided consciousness: Multiple controls in human thought and action. New York: John Wiley.

Hilgard, E. R. (1991). A neodissociation interpretation of hypnosis. In S. J. Lynn \& J. W. Rhue (Eds.), Theories of hypnosis: Current models and perspectives (pp. 83-104). New York: Guilford.

Home Office. (1988). Circular N066/1988: The use of hypnosis by the police in the investigation of crime. London: Author.

Home Office Review of the Hypnotism Act 1952. (1995, October). Report of the expert panel appointed to consider the effects of participation in performances of stage hypnotism. London: Author.

Iacono, W. G. (2008). Effective policing: Understanding how polygraph tests work and are used. Criminal Justice and Behavior, 35, 1295-1308.

Johnson, M. E., \& Hauck, C. (1999). Beliefs and opinions about hypnosis held by the general public: A systematic evaluation. American Journal of Clinical Hypnosis, 10, 10-20.

Kebbell, M. R., Milne, R., \& Wagstaff, G. F. (1999). The cognitive interview: A survey of its forensic effectiveness. Psychology, Crime, and Law, 5, 101-115.

Kebbell, M. R., \& Wagstaff, G. F. (1998). Hypnotic interviewing: The best way to interview eyewitnesses? Behavioral Sciences and the Law, 16, 115-129.

Kebbell, M. R., \& Wagstaff, G. F. (1999). The effectiveness of the cognitive interview. In D. Canter \& L. J. Alison (Eds.), Interviewing and deception (pp. 23-41). Dartmouth, UK: Ashgate.

Kihlstrom, J. F. (2004). Commentary on "précis of the illusion of conscious will" by D. M. Wegner. Behavioral and Brain Sciences, 27, 649-692.

Killeen, P. R., \& Nash, M. R. (2003). The four causes of hypnosis. International Journal of Clinical and Experimental Hypnosis, 51, 195-231.

Kirsch, I. (1991). The social learning theory of hypnosis. In S. J. Lynn \& J. W. Rhue (Eds.), Theories of hypnosis: Current models and perspectives (pp. 439-466). New York: Guilford. 
Kirsch, I., \& Lynn, S. J. (1995). Altered state of hypnosis: Changes in the theoretical landscape. American Psychologist, 50, 846-858.

Kirsch, I., Mobayed, C. P., Council, J. R., \& Kenny, D. A. (1992). Expert judgments of hypnosis from subjective state reports. Journal of Abnormal Psychology, 101, 657-662.

Kleinhauz, M., Horowitz, I., \& Tobin, T. (1977). The use of hypnosis in police investigation: A preliminary communication. Journal of the Forensic Science Society, 17, 77-80.

Kohnken, G., Milne, R., Bull, R., \& Memon, A. (1999). The cognitive interview: A meta-analysis. Psychology, Crime, and Law, 5, 3-27.

Levitt, R. E., Aronoff, G., Morgan, C. D., Overley, T. M., \& Parrish, M. J. (1975). Testing the coercive power of hypnosis: Committing objectionable acts. International Journal of Clinical and Experimental Hypnosis, 23, 59-67.

Lynn, S. J. (1992). A nonstate view of hypnotic involuntariness. Contemporary Hypnosis, 9, 21-27.

Lynn, S. J., \& Nash, M. R. (1994). Truth in memory: Ramifications for psychotherapy and hypnotherapy. American Journal of Clinical Hypnosis, 36, 194-208.

Lynn, S. J., Nash, M. R., Rhue, J. W., Frauman, D. C., \& Sweeney, C. (1984). Nonvolition, expectancies and hypnotic rapport. Journal of Abnormal Psychology, 93, 295-303.

Lynn, S. J., \& Rhue, J. W. (1991a). An integrative model of hypnosis. In S. J. Lynn \& J. W. Rhue (Eds.). Theories of hypnosis: Current models and perspectives (pp. 397-438). New York: Guilford.

Lynn, S. J., \& Rhue, J. W. (Eds.). (1991b). Theories of hypnosis: Current models and perspectives. New York: Guilford.

Lynn, S. J., Rhue, J. W., \& Weekes, J. R. (1990). Hypnotic involuntariness: A social cognitive analysis. Psychological Review, 97, 169-184.

Marmelstein, L. R., \& Lynn, S. J. (1999). Normative, group and hypnotic influences on early autobiographical memory reports. International Journal of Clinical and Experimental Hypnosis, 301, 312-313.

Martin, D. J., \& Lynn, S. J. (1996). The hypnotic simulation index: Successful discrimination of real versus simulating participants. International Journal of Clinical and Experimental Hypnosis, 154, 338-353.

McConkey, K. M., \& Jupp, J. J. (1986). A survey of opinions about hypnosis. British Journal of Experimental and Clinical Hypnosis, 3, 87-94.

McConkey, K. M., Labelle, L., Bibb, B. C., \& Bryant, R. A. (1990). Hypnosis and pseudomemory: The relevance of text context. Australian Journal of Psychology, 42, 197-206.

McConkey, K. M., \& Sheehan, P. W. (1996). Hypnosis, memory, and behavior in criminal investigation. New York: Guilford.

Milgram, S. (1974). Obedience to authority. London: Tavistock.

Mottahedin, I. (1992). Was hypnosis involved in the Nelson case? Contemporary Hypnosis, 9, 158.

Murray, G. J., Cross, H. J., \& Whipple, J. (1992). Hypnotically created pseudomemories: Further investigation into the "memory distortion or response bias" question. Journal of Abnormal Psychology, 101, 75-77.

Norman, D. A., \& Shallice, T. (1986). Attention to action: Willed control of behavior. In R. J. Davidson, G. E. Schwartz, \& D. Shapiro (Eds.), Consciousness and self-regulation (Vol. 4, pp. 1-18). New York: Plenum.

O'Connell, C. N., Shor, R. E., \& Orne, M. T. (1970). Hypnotic age regression: An empirical and methodological analysis. Journal of Abnormal and Social Psychology, 76(Monograph Suppl.), 1-32.

Ofshe, R., \& Watters, E. (1996). Making monsters: False memories, psychotherapy and sexual hysteria. London: Andre Deutsch.

Orne, M. T. (1962). On the social psychology of the psychological experiment: With particular reference to demand characteristics and their implications. American Psychologist, 17, 776-783.

Orne, M. T. (1966). Hypnosis, motivation, and compliance. American Journal of Psychiatry, 122, 721-726.

Orne, M. T. (1970). Hypnosis, motivation, and the ecological validity of the psychological experiment. In W. J. Arnold \& M. M. Page (Eds.), Nebraska Symposium on Motivation (pp. 187-265). Lincoln: Nebraska Press.

Orne, M. T. (1971). The simulation of hypnosis: Why, how, and what it means. International Journal of Clinical and Experimental Hypnosis, 19, 183-210.

Orne, M. T. (1979). The use and misuse of hypnosis in court. International Journal of Clinical and Experimental Hypnosis, 27, 311-341.

Orne, M. T., \& Evans, F. J. (1965). Social control in the psychological experiment: Antisocial behavior and hypnosis. Journal of Personality and Social Psychology, 1, 189-200.

Orne, M. T., Soskis, D. A., Dinges, D. F., \& Orne, E. C. (1984). Hypnotically induced testimony. In G. L. Wells \& E. F. Loftus (Eds.), Eyewitness testimony: Psychological perspectives (pp. 171-215). Cambridge, UK: Cambridge University Press.

Perfect, T. J., Wagstaff, G. F., Moore, D., Andrews, B., Brown, L., \& Cleveland, V. (2007). How can we help witnesses to remember more? It's an (eyes) open and shut case. Law and Human Behavior, 55, 486-496.

Perry, C. (1992). Countering the stereotypes of hypnosis. Contemporary Hypnosis, 9, 150.

Ready, D. J., Bothwell, R. K., \& Brigham, J. C. (1997). The effects of hypnosis, context reinstatement and anxiety on eyewitness memory. International Journal of Clinical and Experimental Hypnosis, 45, 55-67.

Reiser, M. (1980). Handbook of investigative hypnosis. Los Angeles: Lehi.

Reiter, P. J. (1958). Antisocial or criminal acts and hypnosis: A case study. Springfield, IL: Charles C Thomas. 
Rowland, L. W. (1939). Will hypnotized persons try to harm themselves or others? Journal of Abnormal and Social Psychology, 34, 114-117.

Sanders, G. S., \& Simmons, W. L. (1983). Use of hypnosis to enhance eyewitness accuracy: Does it work? Journal of Applied Psychology, 68, 70-77.

Scoboria, A., Mazzoni, G., Kirsch, I., \& Milling, L. S. (2002). Immediate and persisting effects of misleading questions and hypnosis on memory reports. Journal of Experimental Psychology: Applied, 8, 26-32.

Sheehan, P. W., Green, V., \& Truesdale, P. (1992). Influence of rapport on hypnotically induced pseudomemory. Journal of Abnormal Psychology, 101, 690-700.

Sheehan, P. W., \& Perry, C. W. (1976). Methodologies of hypnosis: A critical appraisal of contemporary paradigms of hypnosis. Hillsdale, NJ: Lawrence Erlbaum.

Sheehan, P. W., \& Statham, D. (1988). Associations between lying and hypnosis: An empirical analysis. British Journal of Experimental and Clinical Hypnosis, 5, 87-94.

Sheehan, P. W., \& Tilden, J. (1983). Effects of suggestibility and hypnosis on accurate and distorted retrieval from memory. Journal of Experimental Psychology: Learning, Memory, and Cognition, 9, 283-293.

Sheridan, C. L., \& King, R. G. (1972). Obedience to authority with an authentic victim. Proceedings, 80th Annual Convention $A P A, 45,165-166$.

Silva, C. E., \& Kirsch, I. (1987). Breaching hypnotic amnesia by manipulating expectancy. Journal of Abnormal Psychology, 96, 325-329.

Smith, M. C. (1983). Hypnotic memory enhancement of witnesses: Does it work? Psychological Bulletin, 94, 387-407.

Spanos, N. P. (1986). Hypnotic behavior: A social psychological interpretation of amnesia, analgesia, and "trance logic." Behavioral and Brain Sciences, 9, 449-502.

Spanos, N. P. (1991). A sociocognitive approach to hypnosis. In S. J. Lynn \& J. W. Rhue (Eds.), Theories of hypnosis: Current models and perspectives (pp. 324-361). New York: Guilford.

Spanos, N. P. (1992). Compliance and reinterpretation in hypnotic responding. Contemporary Hypnosis, 9, 7-14.

Spanos, N. P., \& Chaves, J. F. (Eds.). (1989). Hypnosis: The cognitive behavioral perspective. Buffalo, NY: Prometheus.

Spanos, N. P., Cobb, P. C., \& Gorassini, D. R. (1985). Failing to resist test suggestions: A strategy for self-presenting as deeply hypnotized. Psychiatry, 48, 282-292.

Spanos, N. P., Gwynn, M. I., Comer, S. L., Baltruweit, W. J., \& de Groh, M. (1989). Are hypnotically induced pseudomemories resistant to cross-examination? Law and Human Behavior, 13, 271-289.

Spanos, N. P., Quigley, C. A., Gwynn, M. I., Glatt, R. L., \& Perlini, A. H. (1991). Hypnotic interrogation, pretrial preparation, and witness testimony during direct and indirect cross-examination. Law and Human Behavior, 15, 639-653.

Steblay, N. M., \& Bothwell, R. K. (1994). Evidence for hypnotically refreshed testimony. Law and Human Behavior, $18,635-651$.

Troyer, A. K., Moscovitch, M., \& Winocur, G. (1997). Clustering and switching as two components of verbal fluency: Evidence from younger and older healthy adults. Neuropsychology, 11, 138-146.

Udolf, R. (1983). Forensic hypnosis: Psychological and legal aspects. Lexington, MA: Lexington Books.

Vingoe, F. J. (1995). Beliefs of British law and medical students compared to an expert criterion group on forensic hypnosis. Contemporary Hypnosis, 12, 173-187.

Wagstaff, G. F. (1981). Hypnosis, compliance, and belief. Brighton, UK: Harvester.

Wagstaff, G. F. (1982a). Helping a witness remember-A project in forensic psychology. Police Research Bulletin, 38, 56-58.

Wagstaff, G. F. (1982b). Hypnosis and witness recall: A discussion paper. Journal of the Royal Society of Medicine, 75, 793-797.

Wagstaff, G. F. (1984). The enhancement of witness memory by hypnosis: A review and methodological critique of the experimental literature. British Journal of Experimental and Clinical Hypnosis, 2, 3-12.

Wagstaff, G. F. (1989). Forensic aspects of hypnosis. In N. P. Spanos \& J. F. Chaves (Eds.), Hypnosis: The cognitive behavioral perspective (pp. 340-357). Buffalo, NY: Prometheus.

Wagstaff, G. F. (1991). Compliance, belief and semantics in hypnosis: A nonstate, sociocognitive perspective. In S. J. Lynn \& J. W. Rhue (Eds.), Theories of hypnosis: Current models and perspectives (pp. 362-396). New York: Guilford.

Wagstaff, G. F. (1998). The semantics and physiology of hypnosis as an altered state. Contemporary Hypnosis, 15, $149-164$.

Wagstaff, G. F. (1999a). Forensic hypnosis. In I. Kirsch, A. Capafons, E. Cardena-Buela, \& S. Amigo (Eds.), Clinical hypnosis and self-regulation therapy: A cognitive-behavioral perspective (pp. 277-310). Washington, DC: American Psychological Association.

Wagstaff, G. F. (1999b). Hypnotically elicited testimony. In A. Heaton Armstrong, E. Shepherd, \& D. Wolchover (Eds.), Analysing witness testimony (pp. 277-310). London: Blackstone.

Wagstaff, G. F. (2000). On the physiological redefinition of hypnosis: A reply to Gruzelier. Contemporary Hypnosis, $17,154-162$.

Wagstaff, G. F. (2004). High hypnotizability in a sociocognitive framework. In M. Heap, D. Oakley, \& R. Brown (Eds.), The highly hypnotisable person (pp. 85-114). London: Brunner-Routledge.

Wagstaff, G. F., Brunas-Wagstaff, J., Cole, J., \& Wheatcroft, J. (2004). New directions in forensic hypnosis: Facilitating memory with focused meditation. Contemporary Hypnosis, 21, 14-27. 
Wagstaff, G. F., Brunas-Wagstaff, J., Knapton, L., Winterbottom, J., Crean, V., Cole, J., et al. (2004). Facilitating memory with hypnosis, focused meditation and eyeclosure. International Journal of Clinical and Experimental Hypnosis, 52, 434-455.

Wagstaff, G. F., Cole, J., Wheatcroft, J., Marshall, M., \& Barsby, I. (2007). A componential approach to hypnotic memory facilitation: Focused meditation, context reinstatement and eye movements. Contemporary Hypnosis, 3, 97-108.

Wagstaff, G. F., Cole, J. C., \& Brunas-Wagstaff, J. (2007). Effects of hypnotic induction and hypnotic depth on phonemic fluency: A test of the frontal inhibition account of hypnosis. International Journal of Psychology and Psychological Therapy, 7, 27-40.

Wagstaff, G. F., \& Dockar, S. (1985, April). Conceptions of forensic hypnosis: A preliminary investigation. Paper presented at the annual conference of the British Society of Experimental and Clinical Hypnosis, London.

Wagstaff, G. F., \& Frost, R. (1996). Reversing and breaching posthypnotic amnesia and hypnotically created pseudomemories. Contemporary Hypnosis, 13, 191-197.

Wagstaff, G. F., Green, K., \& Somers, E. (1997). The effects of the experience of hypnosis, and hypnotic depth, on juror's decisions regarding the defence of hypnotic automatism. Legal and Criminological Psychology, 2, 65-74.

Wagstaff, G. F., Vella, M., \& Perfect, T. J. (1992). The effect of hypnotically elicited testimony on jurors' judgments of guilt and innocence. Journal of Social Psychology, 31, 69-77.

Webert, D. R. (2003). Are the courts in a trance? Approaches to the admissibility of hypnotically enhanced witness testimony in the light of empirical evidence. American Criminal Law Review, 40, 1301-1327.

Wilson, L., Greene, E., \& Loftus, E. F. (1986). Beliefs about forensic hypnosis. International Journal of Clinical and Experimental Hypnosis, 34, 110-121.

Wolberg, L. R. (1972). Hypnosis: Is it for you? New York: Harcourt Brace Jovanovich.

Woody, E. (1998, December). What is hypnosis? Introduction: Symposium on the neural basis of memory. Symposium conducted at the 5th Internet World Congress for Biomedical Sciences, Hamilton, Ontario, Canada.

Woody, E., \& Farvolden, P. (1998). Dissociation and frontal executive function. American Journal of Clinical Hypnosis, 40, 206-216.

Woody, E. Z., \& Bowers, K. S. (1994). A frontal assault on dissociated control. In S. Lynn \& J. Rhue (Eds.), Dissociation: Theoretical and research perspectives (pp. 52-79). New York: Guilford.

Young, P. C. (1952). Antisocial uses of hypnosis. In L. M. Le Cron (Ed.), Experimental hypnosis (pp. 376-409). New York: Macmillan.

Graham F. Wagstaff is a professor in cognitive social psychology at Liverpool University. In addition to his academic work, he advises the police on subjects including hypnosis and interviewing and has appeared as an expert witness in the High Court. 